\title{
Research of Devdoraki Glacier Based on Satellite Remote Sensing Data and Devdoraki Glacier Falls in Historical Context
}

\author{
G. Kordzakhia ${ }^{1}$, L. Shengelia ${ }^{1}$, G. Tvauri ${ }^{2}$, M. Dzadzamia ${ }^{3}$ \\ ${ }^{1}$ Georgian Technical University, the Institute of Hydrometeorology, Tbilisi, Georgia \\ ${ }^{2}$ I. Javakhishvili Tbilisi State University, Nodia Institute of Geophysics, Tbilisi, Georgia \\ ${ }^{3}$ National Environmental Agency of the Ministry of Environment and Natural Resources Protection of Georgia, Tbilisi, Georgia \\ Email address: \\ giakordzakhia@gmail.com (G. Kordzakhia), larisa.shengelia@gmail.com (L. Shengelia), gena_tvauri@yahoo.com (G. Tvauri), \\ murmandzadzamia@yahoo.com (M. Dzadzamia)
}

\section{To cite this article:}

G. Kordzakhia, L. Shengelia, G. Tvauri, M. Dzadzamia. Research of Devdoraki Glacier Based on Satellite Remote Sensing Data and Devdoraki Glacier Falls in Historical Context. American Journal of Environmental Protection. Special Issue: Applied Ecology: Problems, Innovations. Vol. 4, No. 3-1, 2015, pp. 14-21. doi: 10.11648/j.ajep.s.2015040301.13

\begin{abstract}
The problem of the transportation safety for Mtskheta-Stepantsminda-Larsi road is overviewed. The scientific study of glaciers in the Caucasus started in the first half of the 19th century. From that time the terrestrial observations on glaciers were carried out. The outputs of terrestrial observations resulted in different series of various temporal duration characteristics of glaciers due to the difficulties of field works organization. The data received contain uncertainties and have no sufficient resolution in time and space. With the invention of the Earth's satellites it was determined that satellite remote sensing is the best technology allowing to receive the data with needed regularity both in terms of time and space resolution. The results of various researches show that sometimes the satellite remote sensing data is difficult to interpret and determine needed glacier characteristics. In such cases the data of the terrestrial observations are used for validation of glacier characteristics along with the expert knowledge of corresponding glaciers. This complex approach gives the possibility to adjust glaciers contours and calculate more accurately various characteristics of a glacier. At present the main problem for the safety of the Georgian Military Road in the territory of Georgia is the glacial and hydrological disasters such as ice blocks falls from the Kazbegi glaciations accompanied with the debris, followed by the river bed blockage and natural dam formation, with a consequent break and pass of catastrophic mudflows. The glacial catastrophes of Kazbegi glaciers: Devdoraki, Mna, Gergeti, Abano and Chachi have great impact on Mtskheta-Stepantsminda-Larsi road safety on the territory of Georgia. The biggest catastrophes on the Georgian territory took place due to Devdoraki glacier fell in 1776, 1778, 1785, 1808, 1817, 1832. The Devdoraki glacier listed falls during those years were connected with the pulsation of the glaciers and their increase. In Kazbegi glaciation the environmental disasters occurred in 2002, 2007 and 2014 (twice). It was the result of ice layers movement. Based on the analysis, it was concluded that the creation of the May 17 and August 20, 2014 catastrophic mudflows was not connected with the glacier pulsation.
\end{abstract}

Keywords: Remote Sensing, Glaciers, GIS, Melting \& Accumulation, Climate Change

\section{Introduction}

A thousand years before people from the highland areas needed to study glaciers for reaching the neighboring valleys. Scientific interest in the study of glaciers was pronounced three centuries ago. It was caused by different factors: a study of the dynamics of glaciers and research of scientific facts about the past glaciation ages. At present, to the listed factors, glaciers research necessity is stipulated by: the water provision, surface water level rise in oceans/seas, indication of climate change at regional and global scales.

The importance of the Glaciology is proved by the fact that the glaciers occupied approximately 11\% (16 million square kilometers) of the earth's land area. The glaciers contain a large number of fresh-water $\left(30\right.$ million $\left.\mathrm{km}^{3}\right)$, which is the $2 / 3$ of the earth's fresh water supply.

Modern Glaciology, as a science, was established in 18th century in Switzerland, in 1760. Swiss scientist Benedict de 
Saussure began the research of the Alps. The results were published in his book "Travelling in Alps; 1779-1796". At the same time Benedict de Saussure was the first, who climbed the highest peak of the Alps, Mont Blanc. Thus, he is considered as the founder of the Glaciology and mountain climbing.

Scientific study of the glaciers in the Caucasus was started during the second half of 19th century and was mainly concentrated on transportation safety. At that time the biggest transportation artery was the Mtskheta-Stepantsminda-Larsi road (founded in 1861) connecting Georgia with Russia passing over the Caucasus range. The main problem for the safety of transportation route are glacial and hydrological disasters occurred in the Kazbegi glaciation and having an impact on the mentioned road. Several scientists were researching the existing glaciers characteristics participating in field works trying to determine several characteristics of the glaciers [1-3]. The safety of the transportation was important problem as well. Due to glaciers falls Georgia faced heavy economic losses and casualties. At present this problem remains topical.

\section{Study Area \& Glaciers Survey}

Georgia is a transcontinental country, located in the South Caucasus, between the Black Sea to the West and the Caucasus mountains to the North. The border of Georgia with Russian Federation is located in the North part of the country. The Mtskheta-Stepantsminda-Larsi road passes over the Caucasus range connecting Georgia with Russian Federation.

The present research overviews the problem of the transportation safety for Mtskheta-Stepantsminda-Larsi road (Georgian Military Road). The interests of several neighbors (Armenia, Turkey, partially Azerbaijan) are focused on this road, the shortest way from Georgia to Russian Federation.

The study area is mainly concentrated on the glaciers from Kazbegi glaciation located in Georgian territory. Mountain Kazbegi from the paleographical view is the young (several thousand years) volcanic cone, which belongs to extinct volcano. It seems that the snow-ice cover exist a long time and at present it is much degraded. Snow-ice masses are spread on the massive volcanic peaks and slopes. From the snowfields around the cone ice streams, i.e. glaciers: Devdoraki, Mna, Gergeti, Abano, etc. passes nearly to each gorge.

In fig. 1 Aster DEM (a.) and false color Landsat images (b.) of Kazbegi glaciation is presented.

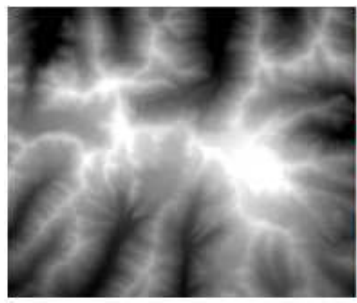

(a)

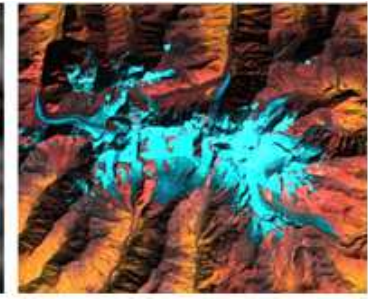

(b)
Figure 1. Aster DEM (a.) and False color Landsat images (b.) of Kazbegi glaciation.
At present the main problem for the safety of transportation route are glacial and hydrological disasters such as glacier falls, the river bed blockage and natural dam formation, with a consequent break and passing of catastrophic flash floods and/or mudflows. Kazbegi glaciers: Devdoraki, Mna, Gergeti, Abano and Chachi are the main source of glacial catastrophe threats of road safety. They are located in the river feeds of the rivers Devdoraki, Mnestskali, Chkeri, Amali. These rivers are the left tributaries of the river Terek.

The biggest catastrophes from Georgian territory took place due to Devdoraki glacier fall in 1776, 1778, 1785, 1808, 1817, 1832 and 2014 (twice) [4, 5].

In fig. 2 the $3 \mathrm{D}$ visualization of Landsat images and Aster DEM (a.) and Google Earth image (b.) of the Kazbegi glacial mountain array are shown. In left parts of a. and b. of this picture the Devdoraki glacier visualizations are presented.

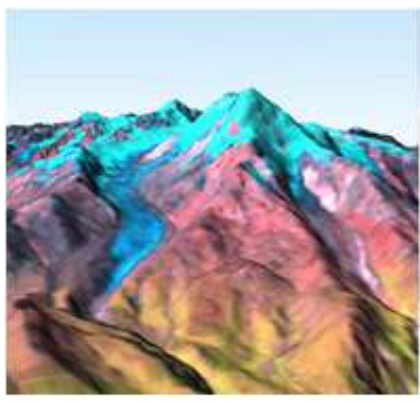

(a)

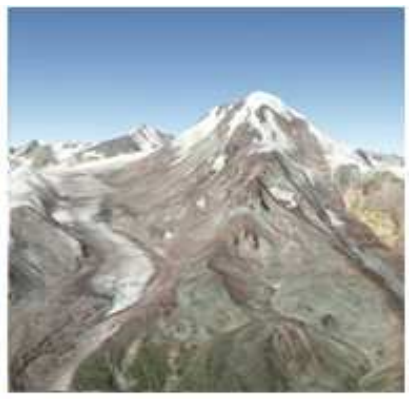

(b)
Figure 2. The $3 D$ visualization of Landsat images and Aster DEM (a.) and Google Earth image (b.) of the Kazbegi glacial mountain array are presented.

It should be noted that the glacier fall took place during the periods $\left(18^{\text {th }}-19^{\text {th }}\right.$ centuries $)$, when the glaciers parameters (area, length, volume) were mainly increased $[1,2,4]$. It is determined that during the second half of the last century the characteristics of the Georgian glaciers are steadily diminishing. The area of the Georgian glaciers decreased by $36 \%$ and the volume - by $48 \%$ consequently. Some glaciers melted away, but the total number of glaciers increased. The length of glaciers was reduced by $600 \mathrm{~m}$ in average. In the lower part of glaciers ice thickness decreased by 50-150 m. At the upper part ice thickness was reduced by 20-30 m [6-9]. The elevation of the lower boundary of the glaciers increased.

In the last century the terrestrial observations on glaciers were carried out. Due to the difficulties of organization and conducting of terrestrial observations the outputs resulted in different series of various temporal duration characteristics of glaciers. The data received contain an uncertainties. From other hand carrying out of such field works are expensive and data gathered have no sufficient spatial and temporal resolution.

With the launch of the Earth's satellites it was determined that satellite remote sensing is the best technology allowing to receive data with needed regularity in terms of both time and space resolution. Some uncertainities remain in the data as the observational tool is too far away from the Earth's surface. So, the necessity for the strong quality assessment/quality control (QA/QC) remains. A lot of studies show that the best method 
for investigation of glaciers are application of satellite remote sensing combined with terrestrial observations and expert knowledge of separate glaciers. Actually, this is the important steps for the QA/QC.

Usually the user is responsible to acquire the data from airborne sensors or/and application of the such data that have already been collected.

The situation with regards to space borne data is rather diverse. Some operational space borne systems collect all possible data free of charge, whenever others gather the highest resolution imagery data only according to special demand, which is rather expensive.

Whenever disasters early warning system is to be realized the special operational space borne system, i.e. specifically satellite images must be applied.

The satellite remote sensing gives possibility of universal, systematic and complex research of glaciers properties and changes. This is due to the fact that satellite remote sensing allows to cover efficiently the interesting regions and dynamically to study such important parameters, as the glacier area, terminus positions at the end of its location, firn line elevation, accumulation and ablation area, the hypsometry $[9,10]$.

\section{Research Methods}

Changes in glacier area and terminus positions are relatively easy to determine using multispectral satellite images.

As mentioned above, glacier contours combined with a digital elevation model (DEM) give possibility to define various glacier parameters. Delineation of glacier contours is possible both manually and automatically based on the corresponding software by the band combination techniques. Human interpretation remains the best tool for extracting high level information from the satellite imagery. Tedious, manual digitalization of glacier boundaries by an operator with good knowledge of the region can produce glacier boundary contours of high quality and accuracy. Automatic delineation of glacier relies on different spectral properties of glacial ice and snow in the visible and the IR part of the electromagnetic spectrum. The greatest difficulty in glacier mapping from remote sensing is the presence of debris cover on glaciers. In those cases, higher resolution satellite images and DEM are used.

According to the methodology developed the following actions are performed for specifying the contours of the glaciers:

- The Google software product Google Earth use satellite images and the satellite sensor ASTER data based on the generated Digital Terrain Model (Aster DEM). It would be noted that the spatial resolution of the satellite Aster DEM is $30 \mathrm{~m}$. GIS systems Google Earth, BEAM Visat and Quantum GIS Lisboa are applied for satellite data processing [11];

- For the glaciers identification its various characteristics (glaciers contours, numerical characteristics of glaciers, etc.) stored in the GLIMS database are used. GLIMSdatabase protected contours are generated based on the Aster sensor data [12].

- For glaciers contours validation Soviet topographical maps (1: 50,000), as well as, the terrestrial observations data are used. It is clear that such data exists only for the certain glaciers and for some years;

- Expert knowledge is applied to research these glaciers.

- Google Earth software package provides high spatial resolution (0.6-1 m) for the Kazbegi glacier array. Satellite image dated by September 1, 2010 allows high accuracy digitalization of the contours of all Kazbegi glaciers.

\section{Results \& Discussions}

The Kazbegi glaciation characteristics: maximum length, area, minimum and maximum elevations, firn line elevation, ablation area determination on the basis of satellite remote sensing are overviewed in $[10,13]$.

In GLIMS- database Devdoraki glacier is presented with three contours. One of them is named by Devdoraki $044517 \mathrm{E} 42715 \mathrm{~N}$ and in World database is registered as SU4G08011048. The contours of two relatively small glaciers are registered only in GLIMS database, namely by G044532E42709N and G044537E42706N codes. These two contours, after detailed study of high resolution satellite data, as well as based on the analysis of hypsometric curves are assigned to the Devdoraki glacial basin.

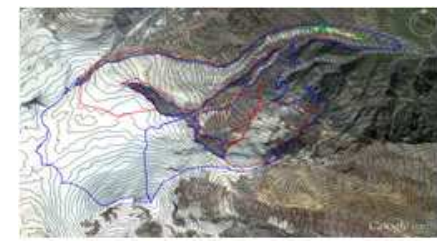

(a)

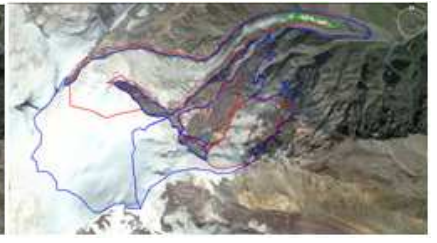

(b)
Figure 3. The Devdoraki glacier contours together with height isoclines. Part a. Devdoraki glacier adjusted contours are given together with height isoclines and in part $b$. consequently the corrected precise contours of Devdoraki glacier are shown. Registered contours from the GLIMS database are indicated with red color, the adjusted contours defined from satellite remote sensing data are presented with blue color and the glacier surface areas free of debris are shown by green color.

In fig. 3 the Devdoraki glacier contours are shown. In fig. 3 part a. Devdoraki glacier adjusted contours are given together with height isoclines and in part $\mathrm{b}$. consequently the corrected precise contours of Devdoraki glacier are shown. Registered contours from the GLIMS database are indicated with red color, the adjusted contours defined from satellite remote sensing data are presented with blue color and the glacier surface areas free of debris are shown by green color.

As it is shown in fig. 3 the significant part of the Kazbegi plateau refers to Devdoraki glacier. This decision was made as a result of the use of digital terrain model. In particular, the Devdoraki glacier watershed was corrected using the isoclines received from Aster DEM. Thus, the glacier borders were 
estimated based on corrected watershed. The elevation isoclines are traced by steps 5,10 , and $30 \mathrm{~m}$ resolution.

In fig 4 the comparison of Devdoraki contours with the former USSR topographic map is presented.

Fig. 4 includes $30 \mathrm{~m}$ resolution drawn isoclines and adjusted contours defined on the basis of precise watershed. Thus, the significant difference between registered contours from GLIMS database and the adjusted contours received from the data of satellite remote sensing is a result of more precise definition of watersheds. Hence, the contours received from the remote sensing are more precise.

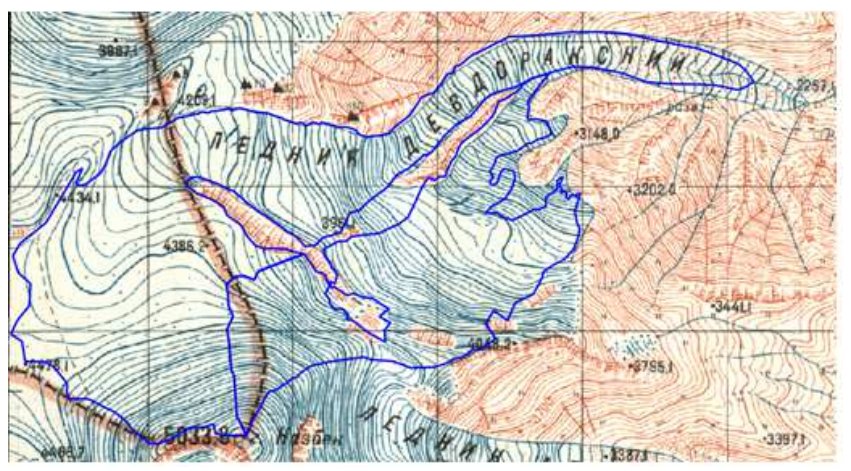

Figure 4. The comparison of Devdoraki contours with topographic map.

Table 1. The characteristics of the Kazbegi glaciations in Georgian territory. Data received from the satellite remote sensing are presented in columns marked by (1); Data from USSR catalogue are shown in the columns marked by (2).

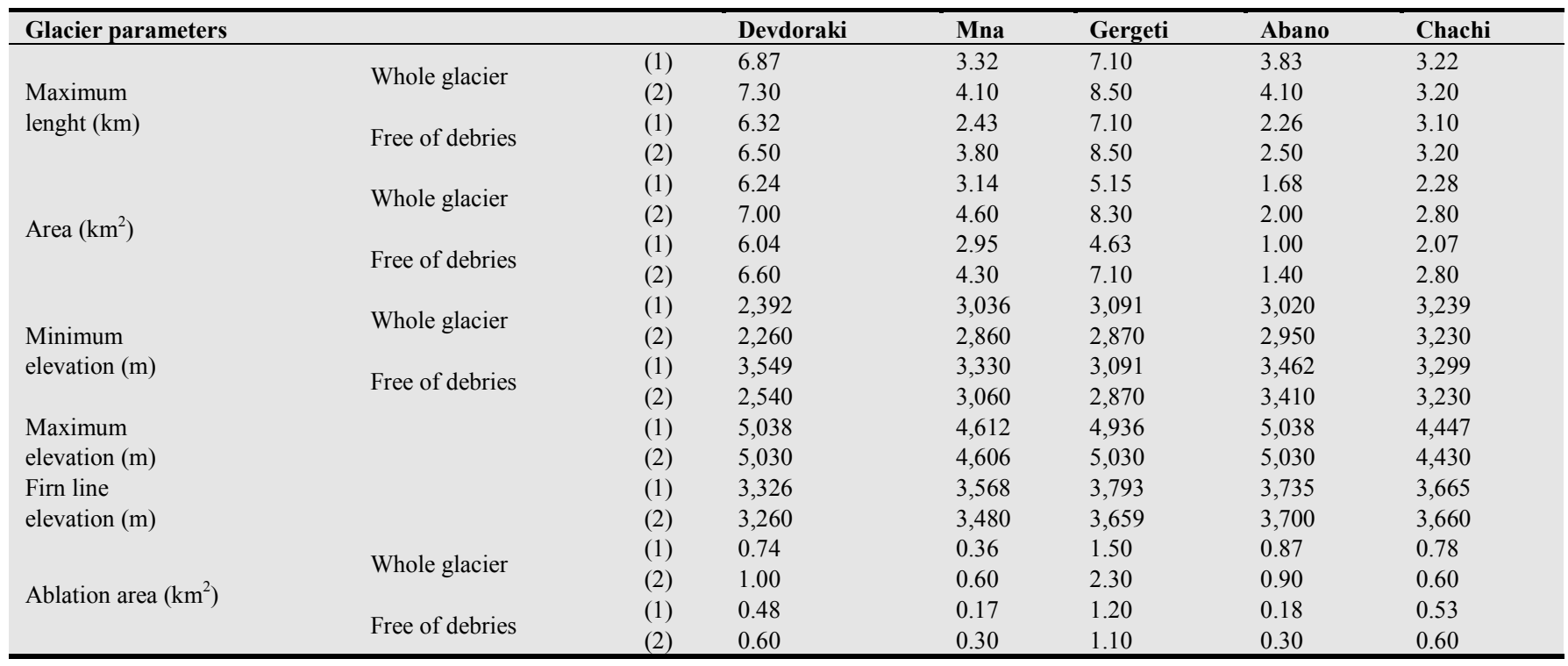

Comparison of a topographic map with contours received from the data of satellite remote sensing (fig. 4) shows that these fields formed entire Devdoraki glacier in the past.So, for comparison of Devdoraki glacier characteristics (area, length etc.) created from satellite remote sensing the joint contour is applied. This data is compared with the Devdoraki glacier data from the USSR glaciers catalogue. In reference to the glacier square: the Devdoraki (SU4G08011048 contour) direct area is equal to 4.05 square $\mathrm{km}$, united G044532E42709N and G044537E42706N contours area is 2.19 square $\mathrm{km}$. Their total area is 6.24 square $\mathrm{km}$.

In Table 1 the Kazbegi glaciation (glaciers in Georgian territory: Devdoraki, Mna, Gergeti, Abano, Chachi) parameters, such as: length, area, minimum elevation, firn line elevation, ablation area defined from the satellite remote sensing data (columns marked by (1)) and from the USSR glaciers catalogue (columns marked by (2)) are presented.

Comparison of the received results from satellite remote sensing with the data from the USSR catalogue [14] is presented in Table 1 (the time gap between them is approximately 50 years). It should be noted that complex research of the glaciers using the data from different sources such as: satellite remote sensing, terrestrial observations and expert knowledge are effective for accurate determination of glaciers main characteristics.

Based on the detailed comparison of the output data received using the satellite remote sensing provided with similar data from the glaciers catalogue it can be concluded that during the last 50 years all the characteristics of the Kazbegi glaciers change:

- The minimum elevation and firn line altitude are increasing;

- The length and area as well as the ablation area are decreasing.

$3 \mathrm{D}$ visualization of Devdoraki glacier contours are presented on fig.5 for the evidence. Registered contours from the GLIMS database are indicated with red color, the adjusted contours received from the data of satellite remote sensing are presented with blue color and the glacier surface areas free of debris are shown by green color. The big differences due to adjusting the Devdoraki glacier contours are clearly shown comparing the red and blue colors on fig.5. 


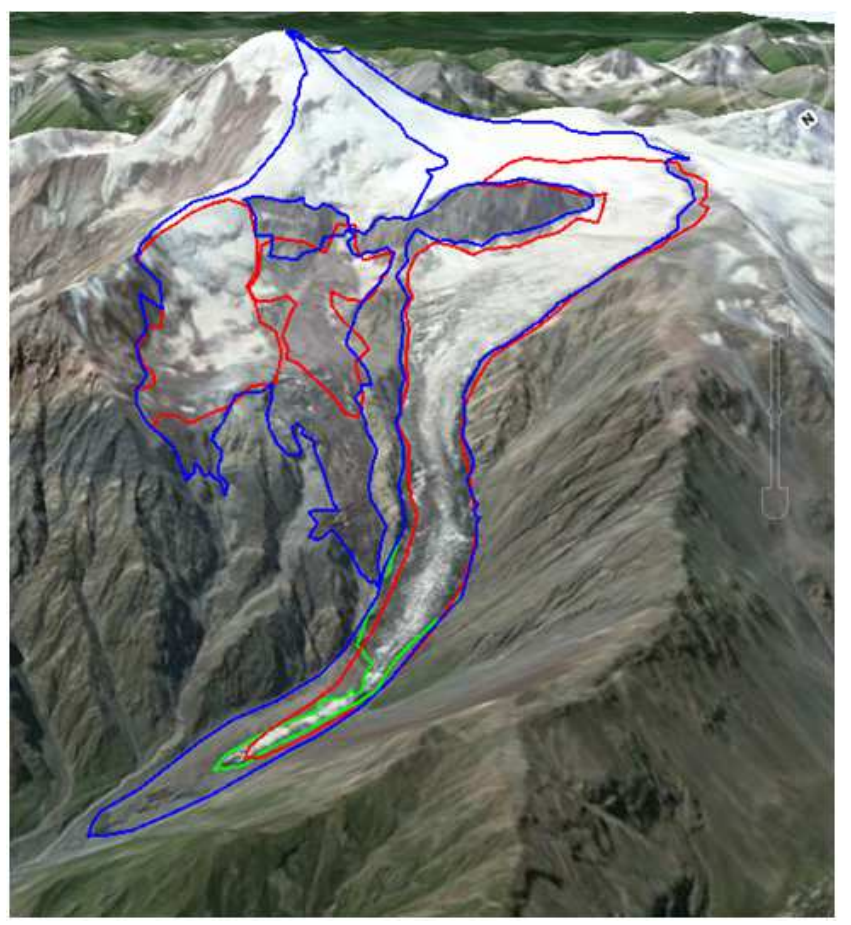

Figure 5. $3 D$ visualization of Devdoraki glacier contours. Registered contours from the GLIMS database are indicated with red color, the adjusted contours received from the data of satellite remote sensing are presented with blue color and free of debris areas are shown by green color.

In fig. 6 Devdoraki glacier satellite images: a. August 31, 1989 from Landsat 4 TM, (generating thematic maps) and b. August 28, 2014 from Landsat 8 OLI are presented. Glacier Devdoraki contours digitalization presented on these images are manually done according to the Google Earth Digital Globe high resolution satellite image, dated January 1, 2010.

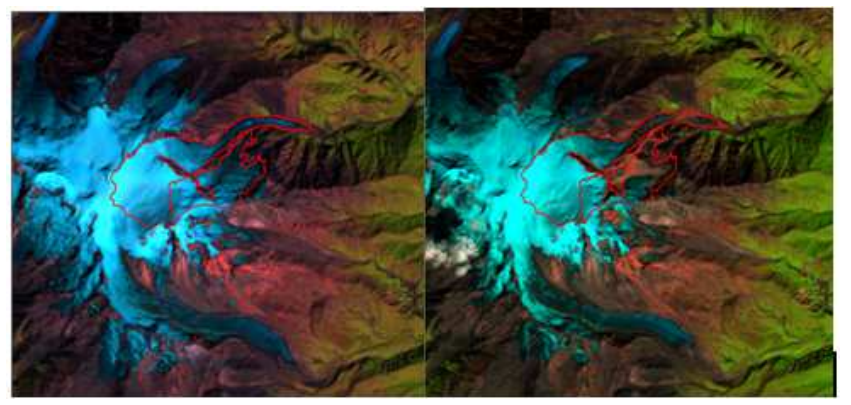

(a)

(b)

Figure 6. Devdoraki glacier false color satellite images: (a.) August 31, 1989 from Landsat 4 TM and (b.) August 28, 2014 from Landsat 8 OLI.

The latest changes in Devdoraki glacier development in light of glacier fall of the 2014 can be defined by comparison of the images from fig. 6 part a. and part b. This allows to define latest modification for the period preceding the August 20, 2014. In fig. 6 part b. is clearly shown the place (the rose circle on the figure) of the collapse of the Devdoraki glacier in 2014.

The biggest scale and the strongest natural catastrophes are observed from the Kazbegi glaciations, namely: Devdoraki glacier from Georgian side and Kolka glacier from the Osetian side. The detailed information about Devdoraki mudflows comes from the time of the Mtskheta-Stepantsminda-Larsi road construction. The biggest catastrophes on the Georgian territory took place due to Devdoraki glacier fell in 1776, 1778, $1785,1808,1817,1832$. The largest scale glacier disaster was observed for Devdorki glacier in 1832. The elevation of created dam was $90 \mathrm{~m}$ and generated reservoir, fully covered the territory of village Gveleti. Recently (2002) the mudflow from the Kolka glacier killed 2 hundred humans and several mln. cubic meter of stone is still kept in Karmadon gorge. Devdoraki glacier advances in 1842, 1843 and 1855 caused small ice-stone mudflows not reaching r. Terek valley. Devdoraki glacier advances in 1865-1875, 1886-1887 and 1893-1904 at the distances of 241.0, 44.8 and $55.5 \mathrm{~m}$ correspondingly did not cause mudflows.

The main reason of the glacial mudflows genesis are consequences of the glaciers subduction. Most of the mountainous glaciers are characterized by rapid pulsing movement. This is a result of the processes going inside the glacier, i.e., fast change of glacier bed conditions and distribution of substances in accumulation and ablation area. There are pulsating glaciers (e.g. Kolka and Devdoraki), which are characterized by sharp advancing of the glacier body the so-called surge accompanied by glacier falls.

When glacier retreats the glacier tongue, due to restricted feeding (result of decreasing of snow precipitation and reduction of its accumulation in firn field) is grinded. Therefore, the crevices are created on the glacier tongue that make prerequisites for moraine material accumulation (rocks and their debris that falls on glacier surface).

In these places due to high temperatures and frequent precipitation on the surface of glacier the certain amount of water is accumulated. It will break the created dams capturing all the remaining ice and moraine material. As a result the destructive mudflows are created.

Obviously, the mudflows that took place in the past were the result of the glaciers such pulsation. At that time periods the characteristics of the Georgian glaciers were mainly increasing.

Last catastrophic events occurred in May and August, 2014 during the period when the characteristics of the Georgian glaciers were steadily diminishing [5].

Based on video, photo material analysis, it can be concluded that the creation of the May 17 and August 20, 2014 catastrophic mudflows are not connected with the pulsation of the Devdoraki glacier. In May 17, 2014 from Kazbegi slope at 4, $700 \mathrm{~m}$ elevation was cut ice block, with the volume of 5 million cubic meters. In Fig. 3 part b. the area of the collapse of the glacier is clearly shown and the place of the accident is no longer covered by ice. This mass fell down along 80-85 degrees inclined slope below 2, $500 \mathrm{~m}$. Then it jumped over the Devdoraki glacier tongue and stroke the left side of the narrow gorge. The ice mass from the mountain slope was accompanied with the vulcanic slag. Vise versa can also be considered, i.e., vulcanic slag was off first and then it was accompanied with ice. 


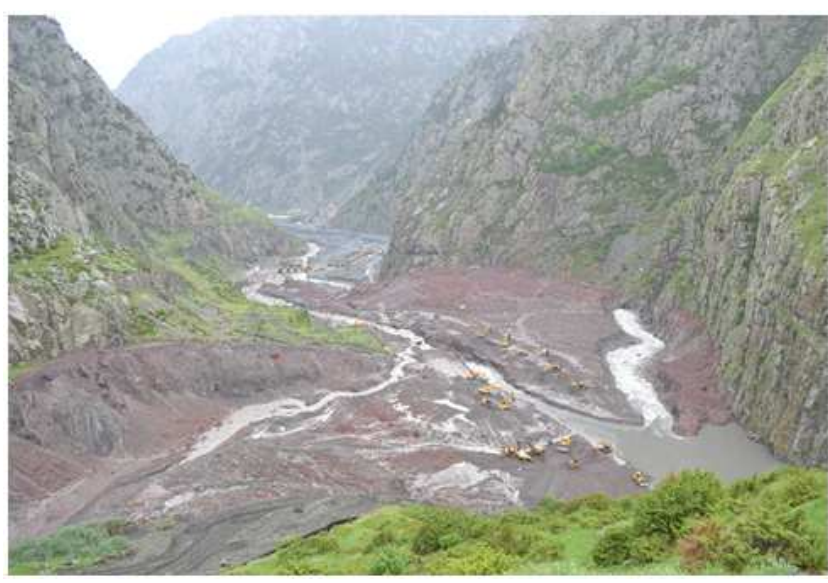

Figure 7. The red trace of the volcanic slag on the sides of the gorge and river bed.

The red trace of the volcanic slag is well reflected in the area's of the strike of the gorge sides and debris flow trace from the source to the confluence (fig.7). Mudflow material surface that arrived in the r. wTerek valley also was red due to the vulcanic slag.

The torrential stream generated due to the ice block collapse into pieces. Water/ice masses mixed with moraine material and vulcanic slag (red slag pieces, including andesite $\&$ dacite rock material). Generated semi-viscous mass passed through narrow Devdoraki-Amali gorge with the speed of $100 \mathrm{~km} / \mathrm{h}$ in 4-5 min maximum.

Semi-viscous mass stream blocked r. Terek riverbed and artificial reservoir was established (fig. 8).

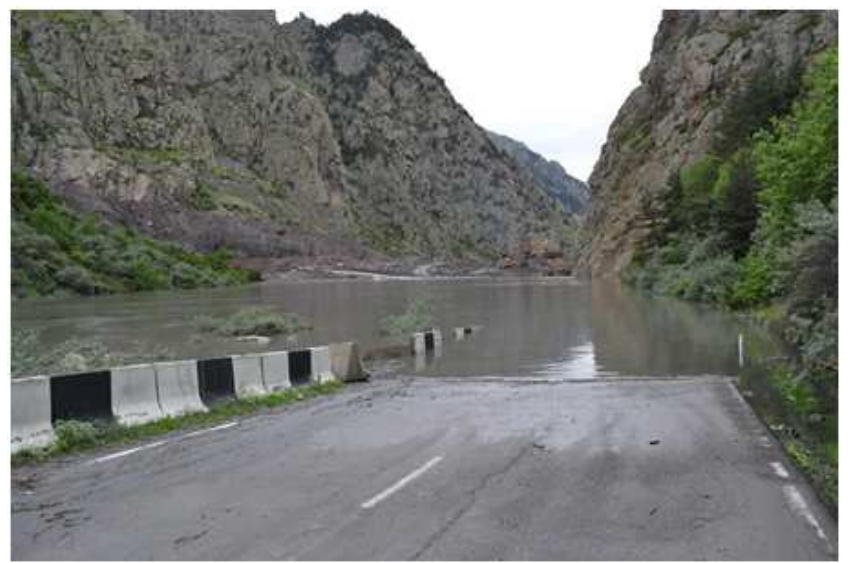

Figure 8. The Terek river bed blockage.

The consequences were heavy. Outgoing pipeline was exploded. Casualties totaled to 4 persons. Established artificial reservoir occupied the area about 2 hectares and the pond was $15 \mathrm{~m}$ deep. Luckily water was discharged by under a construction derivation tunnel of hydropower station. The Mtskheta-Stepantsminda-Larsi strategic road was closed for a long-term time.

It should be noted that in May 17, 2014, the following extra phenomenon was observed: the white colour gas appeared in 1-1.5 hour from the glacier torrent pass, in the foot of the areal of ice block fall. In May 18, 2014 instead of this gas the black color fume appeared in the same place. From the distance it was seen as heavy, viscous "mushroom-shaped" formation. Despite the wind the smoke (maybe dust) did not change its shape and covered the surface for 3-4 hours. Very likely, the gas formation of the dark colour is the dust created as a result of destruction of the moraine material or/and vulcanic slag from the glacier slope. However, it can not be excluded gas-thermal action of the volcano as well.

Concerning the catastrophic event on Devdoraki glacier in August 20, 2014 it can be noted that the natural disaster was provoked by heavy rain and the lake created below the glacier tongue accompanied by the fall of a large mass of ice from the glacier tongue. The consequences of this tragedy were heavy. Casualties totaled to 2 persons, newly constructed hydropower station was destroyed. The existing infrustructure was damaged: Mtskheta-Stepantsminda-Larsi road was ruined and traffic was closed for a long time, the gas pipeline was broken, the customs was damaged.

It should be noted that throughout the history of the survey of Devdorak glacier such big scale and strong catastrophe was not observed twice a year.

In fig. 9 Devdoraki glacier for February 10, 2015 is shown. Empty locations of big depth in Devdoraki Glacier's body are observed. The places (ponds), where the ice, fused are presented with red arrows, apparently as a result of thermal exposure.

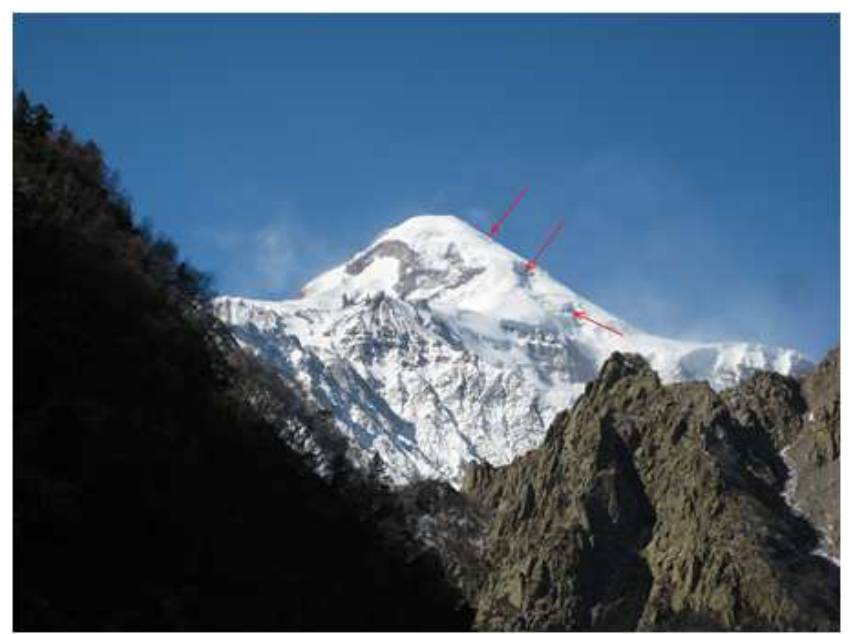

Figure 9. Devdoraki glacier. February 10, 2015. The places (ponds), where the ice fused are presented with red arrows.

So the place of the collapse of Devdoraki glacier (fig 6) may have the same explanation.

These issues are the subject of further researches.

\section{Conclusion}

The problem of the transportation safety for MtskhetaStepantsminda-Larsi road is overviewed. At present the main problem for the safety of transportation route are glacial and hydrological disasters.

The study area is mainly concentrated on the territory occupied by the glaciers from Kazbegi glaciation that are 
located in Georgian territory and adjacent terrain, where the Mtskheta- Stepantsminda-Larsi road passes.

The natural disasters that had significant impact on Mtskheta- Stepantsminda-Larsi road are glacier falls from the Kazbegi glaciation, accompanied with the river bed blocking and natural dam formation, with a consequent break and passing of catastrophic mudflows. The biggest catastrophes from Georgian territory took place due to Devdoraki glacier fall in 1776, 1778, 1785, 1808, 1817, 1832 and 2014 (twice).

The detailed research of the Kazbegi glaciers: Devdoraki, Mna, Gergeti, Abano etc. are made to study, analyze and forecast these processes.

In the last century the terrestrial observations on glaciers were carried out. Due to the difficulties of organization and conducting of terrestrial observations the outputs resulted in different serries of various temporal duration characteristics of glaciers. The data received contain an uncertainities. From another hand carring out of such field works are expensive and data gathered have no sufficient spatial and temporal resolution.

With the launch of the Earth's satellites it was determined that satellite remote sensing is the best technology allowing to receive data with needed regularity in terms of both time and space resolution. Some uncertainities remain in the data as the observational tool is too far away from the Earth's surface. So, the necessity for the strong quality assessment/quality control (QA/QC) remains. Sometimes the satellite data often are hard to interpret and determine the needed glacier characteristics. A lot of studies show that the best method for investigation of glaciers are application of satellite remote sensing data combined with terrestrial observations and expert knowledge of separate glaciers. Actually, this is the important steps for the QA/QC.

It would be noted that whenever the glacial catastrophic events early warning system is to be realized the special operational space borne system i.e. specifically satellite images are to be applied.

Based on the detailed comparison of the output data received using the satellite remote sensing provided with similar data from the glaciers catalogue it can be concluded that during the last 50 years all the characteristics of the main glaciers from East Georgia change:

- The minimum elevation and equilibrium line altitude are increasing;

- The length and area as well as the ablation area are decreasing.

Researches and corresponding analysis show that the impact of modern climate change, i.e., glaciers retreat due to modern warming is well expressed for the considered glaciers from Kazbegi glaciation.

Consequences of the glaciers subduction are the main reasons of the glacial mudflows genesis. Most of the mountainious glaciers are characterized by pulsation. Snow-ice glacier mass is fed through the gravitational movement. Pulsation of mountain glaciers is characterized by a different velocity of spreading ahead and retreat of glaciers periodically. Obviously, the mudflows that took place in the past (from the glaciers observations starting from the end of the 19th century) were the result of the glaciers pulsation. At that time periods characteristics of the Georgian glaciers were steadily increasing.

During 2014 two strong catastrophes were observed and from the second half of the last century the characteristics of the Devdoraki glacier are steadily diminishing.

It should be noted that throughout the history of the survey of Devdoraki glacier such big scale and strong catastrophe was not observed twice a year.

Analysis show that the creation of the May 17 and August 20, 2014 catastrophic mudflows is not connected with the pulsation of the glacier. In May 17, 2014 from Kazbegi slope at 4, 700 m elevation was cut ice block, with the volume of 1 million cubic meters. This mass fell down along 80-85 degrees inclined slope below 2, $500 \mathrm{~m}$. Then it jumped over the Devdoraki glacier tongue and stroke the left side of the narrow gorge. The red trace of the volcanic slag is well reflected in the area's of the strike of the gorge sides and debris flow trace from the source to the confluence.

The torrential semi-viscous passed through narrow Devdoraki-Amali gorge blocked r. Terek riverbed and artificial reservoir was established. It was accompanied by the creation of the white colour gas in the foot of the areal of ice block fall. The next day it was changed by the black color fume. Despite the wind the smoke (maybe dust) did not change its shape and covered the surface for 3-4 hours. Very likely, the gas formation of the dark colour is the dust created as a result of destruction of the moraine material or/and vulcanic slag from the glacier slope. However, it can not be excluded gas-thermal action of the volcano as well.

This last conclusion is promoted by the latest data of Devdoraki glacier from the February 10, 2015 representing the places (ponds) fused in Devdoraki glacier that may have the same explanation.

The consequences of the May 17 and August 20, 2014 catastrophic mudflows was heavy: human deaths were reported, existing infrustructure was damaged, MtskhetaStepantsminda-Larsi road was ruined, traffic was closed for a long time, the gas pipeline exploded, newly constructed hydropower station was destroyed etc.

6. Acknowledgment

The research is carried out in frames of the Shota Rustaveli National Foundation of Georgia that supported research Grant Project FR/586/9-110/13.

The authors are grateful to the specialists of Hydrometeorological Department of National Environmental Agency of Georgia for materials (mainly Figures: 7-9) related to the catastrophic events having place in Devdoraki glacier and surrounding area in May 17 and August 20, 2014.

\section{References}

[1] Abikh G.V. (1877). Neskolko slov o sostoianii v nastoiachee vremia Devdorakskogo lednika. - Izvestia Kavkazskogo otdela IRGO, t. V, 57-64 (in Russian). 
[2] Zaporojchenko E.V., Chernomorets S.S. (2004). Istoria i izuchennost Kazbegskikh zavalov. // Vestnik Kavkazskogo gornogo obchestva, Piatigorsk, № 5, 33-54 (in Russian).

[3] V. Tsomaia (1983), Opasnye gidrometeorologicheskie javlenija na Kavkaze. L., 158-184 (in Russian)

[4] A. N. Bojinski, S.S. Chernomorets 2007). Modelirovanie Kazbekskikh lednikovikh zavalov XVIII-XIX vekov. Materiali gliatsiologicheskikh issledovanii, vip. 103, 91-95.

[5] Tavasiev R. A., Galushkin I.V. (2014). Kamenno-ledovi obval s gori Kazbek 17 Maia 2014 goda. Vestnik Vladikavkazskogo nauchnogo tsentra, tom 14 №2, 43-45.

[6] Chris R., Stokes V., Stephen D. Gurney, Maria Shangedanova, Victor Popovnin (2006). Late-20th century changes glacier extent in the Caucasus Mountains, Russia/Georgia. Journal of Glaciology, Vol. 52 No. 176, 99-109.

[7] Magnus Sylvén, Rasmus Reinvang, Žanete Andersone-Lilley (2008).Climate Change in Southern Caucasus: Impacts on nature, people and society, WWF Norway, WWF Caucasus Programme, 10-31.

[8] [Von Ina Keggenhoff, Tatjana Keller, Mariam Elizbarashvili, Ramin Gobejishvili und Lorenz King (2011). Naturkatastrophen durch Klimawandel im Kaukasus? Hochwasser und Hanginstabilitaten in Georgien immer haufiger. Spiegel der Forschung, N2, 16-23.

[9] Shengelia L.; Kordzakhia G.; Tvauri G.; Davitashvili T.; Begalishvili N. (2012). Possibilities of the use of remote sensing technologies for the estimation of modern climate change impact on the Caucasus glaciers. Monthly Scientific-Reviewed Magazine of Georgian National Academy of Sciences „Metsniereba da Technologiebi” (Science and Technologies”), №4-6, 25-30, (in Georgian).

[10] Petri Pellikka, Gareth Rees W. (2010). Remote Sensing of Glaciers. Taylor \& Francis Group, London, UK, 340.

[11] Bolch, T., and Kamp, U. (2005). Glacier Mapping in High Mountains Using DEMs, Landsat and ASTER Data, Grazer Schriften der Geographie und Raumforschung, In: Proceedings 8th International Symposium on High Moutain Remote Sensing Cartography, vol 41, 20-27 March 2005. La Paz, Bolivia, 13-24.

[12] Raup, B.H.; A. Racoviteanu; S.J.S. Khalsa; C. Helm; R. Armstrong; Y. Arnaud (2007). "The GLIMS Geospatial Glacier Database: a New Tool for Studying Glacier Change". Global and Planetary Change 56, 101-110.

[13] Kordzakhia G., Shengelia L., Tvauri G., Tsomaia V., Dzadzamia M., (2014). Satellite Remote Sensing Outputs of the Certain Glaciers in theTerritory of East Georgia. Egyptian Journal of Remote Sensing and Space Sciences. www.elsevier.com

[14] Tsomaia, V.S., Drobishev, O.A., (1977). Glaciers Catalog of the USSR, the North Caucasus, Leningrad,Gidrometeoizdat, Vol. 8. (In Russian), 71. G. Eason, B. Noble, and I. N. Sneddon, "On certain integrals of Lipschitz-Hankel type involving products of Bessel functions," Phil. Trans. Roy. Soc. London, vol. A247, pp. 529-551, April 1955. (references) 